\title{
APLICAÇÃO DE MÉTODOS MATEMÁTICOS NO DIMENSIONAMENTO DA POTÊNCIA NECESSÁRIA PARA A IRRIGAÇÃO ATRAVÉS DE MOTORES ELÉTRICOS
}

\author{
Luís Roberto Almeida Gabriel Filho ${ }^{1}$
}

Juliano Aparecido Vérri ${ }^{2}$

Camila Pires Cremasco Gabriel ${ }^{3}$

Daniel dos Santos Viais Neto ${ }^{4}$

RESUMO: É comum nas áreas rurais a utilização de métodos de irrigação que consistem em bombear a água de açudes, lagoas e rios para irrigar a terra onde está sendo cultivada determinada cultura. Em geral esse bombeamento é feito por motores movidos á energia elétrica ou á óleo diesel. Este trabalho visa avaliar os motores elétricos de baixa potência que são usados para irrigar pequenas áreas plantadas através de bombeamento de água de açudes, lagoas etc. Os métodos a serem usados competem á aplicação da Física e do Calculo Diferencial e Integral, através do uso de conceitos,integrais definidas e do uso de sólidos de revolução para simulação. Poderão ser feitas associações entre

\footnotetext{
${ }^{1}$ Licenciado em Matemática (FCT/UNESP), Mestre em Matemática Pura (ICMC/USP), Doutor em Agronomia/Energia na Agricultura (FCA/UNESP) e Pós-doutorando em Agronomia/Energia na Agricultura (FCA/UNESP), Professor Assistente Doutor da CET/UNESP - Tupã/SP. gabrielfilho@tupa.unesp.br.

${ }^{2}$ Licenciado em Matemática (FACLEPP/UNOESTE) e Mestrando em Agronomia/Irrigação e Drenagem (FCA/UNESP). ${ }^{3}$ Licenciada em Matemática (FCT/UNESP), Mestre em Matemática Pura (DM/UFSCar), Doutora em Agronomia/Energia na Agricultura (FCA/UNESP) e Pós-doutoranda em Bioestatística (IB/UNESP), Professora Assistente da FATEC Presidente Prudente. camila@fatecpp.edu.br.

4 Licenciado e Bacharel em Matemática (ICMC/USP), Mestre em Matemática Pura (ICMC/USP) e Doutorando em Agronomia/Irrigação e Drenagem (FCA/UNESP), Professor Associado da FATEC - Presidente Prudente. dvneto@fatecpp.edu.br.
} 
vazão de água, potência necessária para o serviço, a quantidade de tempo que a reserva de água sustenta o bombeamento. Depois de feito os cálculos pode se concluir sobre o tipo de motor e potencia mais adequada para tal serviço. Este projeto visa avaliar o desempenho de motores elétrico de baixa potencia no bombeamento de água através de métodos pertinentes ao calculo diferencial e integral e ao mesmo tempo poder mostrar uma das várias aplicações desta disciplina. Após os cálculos realizados espera-se obter conclusões sobre os motores elétricos e fazer a associação do serviço que é recomendado para o seu uso. Serão utilizados métodos do cálculo diferencial e Integral para a avaliação do desempenho do motor e conceitos da Física para determinação e associação entre potência dissipada e vazão de água.

Palavras-chave: irrigação, dimensionamento, energias renováveis.

\section{INTRODUÇÃO}

É comum nas áreas rurais a utilização de métodos de irrigação que consistem em bombear a água de açudes, lagoas e rios para irrigar a terra onde está sendo cultivada determinada cultura, a Figura 1 ilustra tal método. 


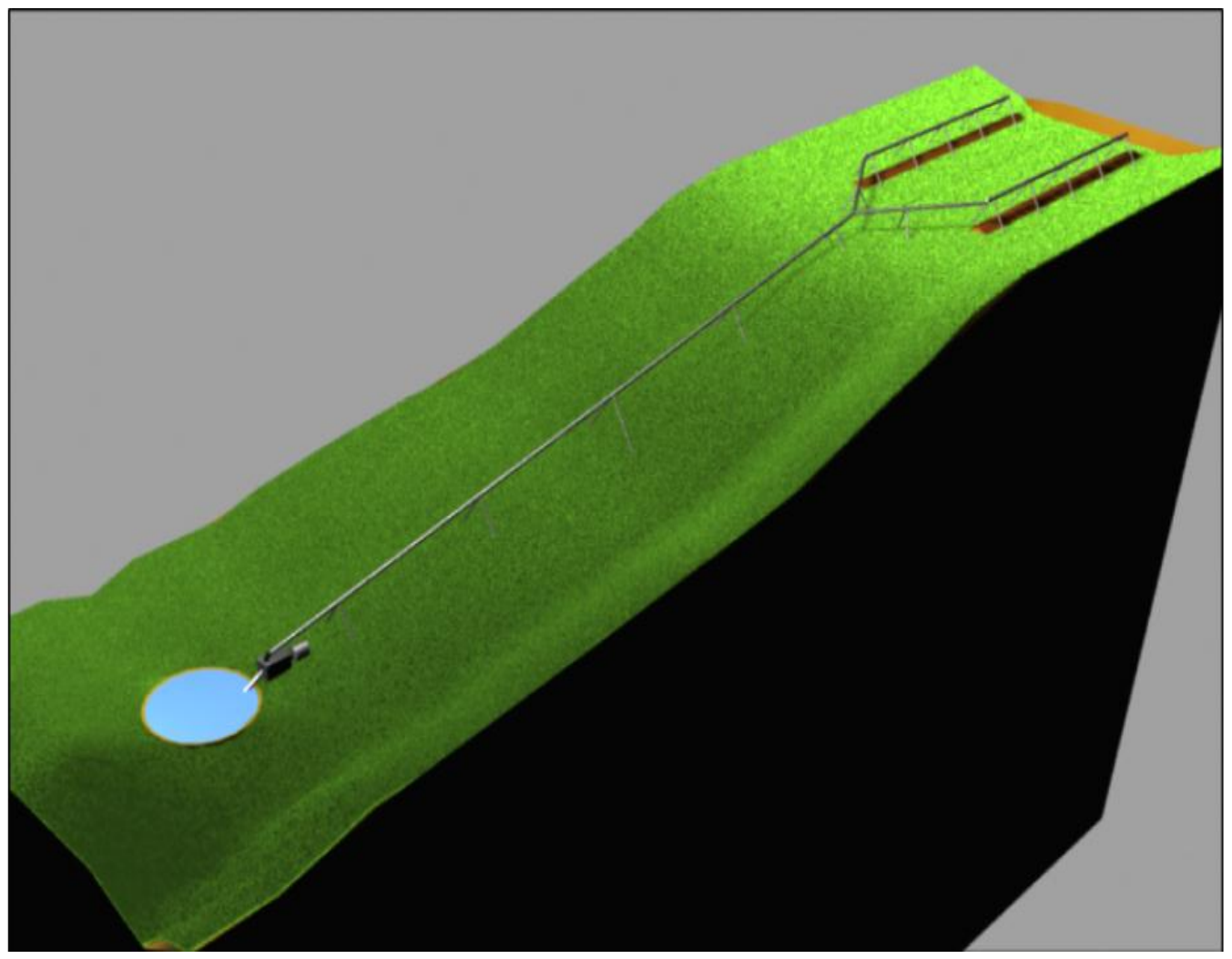

Figura 1. Visualização de um sistema de irrigação.

Em geral esse bombeamento é feito por motores movidos á energia elétrica ou á óleo diesel. Nas pequenas áreas plantadas, como por exemplo plantações de verduras e hortaliças os motores elétricos de baixa potência são os mais usados em geral, isso ocorre devido á sua economia com relação à energia consumida e a boa performance para o serviço.

Vamos fazer uma simulação de uma dessas situações e através do Cálculo Diferencial e Integral e de alguns conceitos de Física vamos determinar as variações e relações entre alguns fatores envolvidos na irrigação, que são; potência da bomba, volume de água contido no açude, variação do nível da água etc.

\section{DESENVOLVIMENTO}


Considerando o açude cheio com uma superfície aproximada a de um círculo e certa profundidade, a primeira questão a esclarecer é se o volume de água contido no açude é suficiente para irrigar conforme as condições exigidas em determinada situação.

Vamos considerar um plano cartesiano em que o eixo das abscissas passa sobre a superfície da água e o eixo das ordenadas passa pelo centro do açude e mais uma parábola em que suas alças passam aproximadamente pela lateral do açude, como na Figura 3.

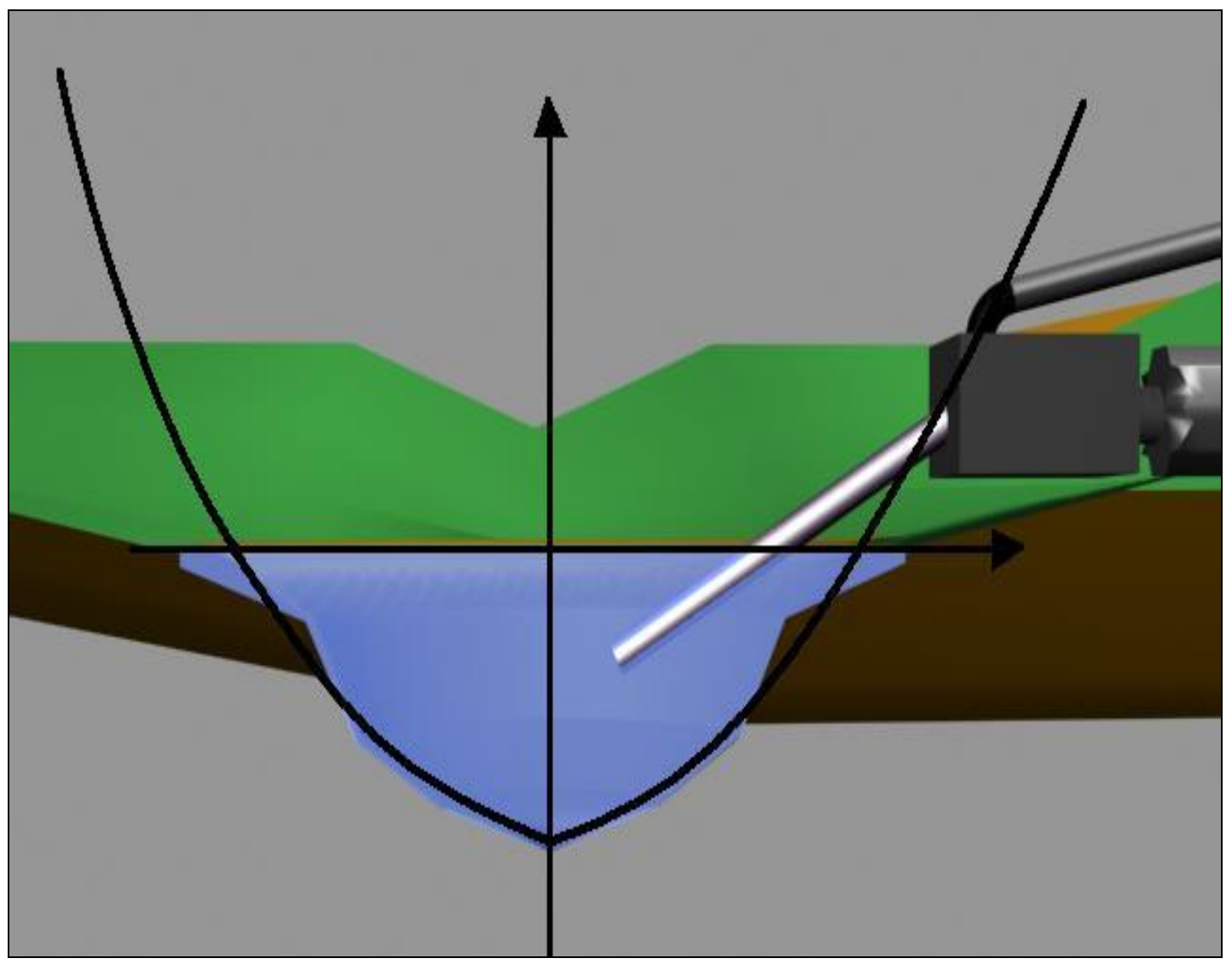

Figura 3. Parábola aproximada ao açude.

Com o eixo das ordenadas passando pelo centro do açude podemos encontrar o ponto correspondente a profundidade do açude da forma $(0, p)$ e os pontos laterais correspondentes a margem, da forma $(-d / 2,0)$ e $(d / 2,0)$, onde $d$ é o diâmetro. 


\section{Periódica Eletrânica

Depois de obtida a função $g(y)$, pode-se calcular o volume do sólido gerado pela rotação da parábola em torno do eixo das ordenadas (Figura 4).

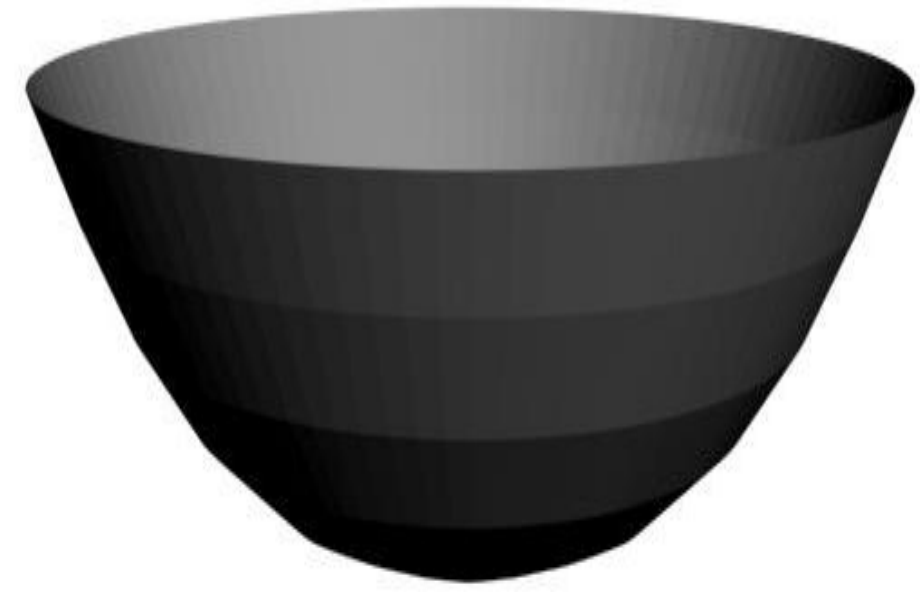

Figura 4. Sólido gerado pela rotação da parábola em torno do eixo y.

Segundo LEITHOLD (1994) o cálculo do volume do sólido de revolução pode ser calculado através da seguinte integral;

$$
V=\lim _{|\Delta| \rightarrow 0} \sum_{i=1}^{n} \pi[g(y)]^{2} \Delta_{i y}=\pi \int_{a}^{b}[g(y)]^{2} d y
$$

Através desta integral também é possível calcular a variação do nível da água quando se sabe o volume de água bombeado.

Segundo CALÇADA 1998, a aplicação do teorema da energia Cinética a certa porção de água, de massa $m$ e volume $V$ conduz a seguinte expressão:

$$
T_{R}=\frac{m v^{2}}{2}-\frac{m v_{0}^{2}}{2}
$$

Sendo $P_{X}$ o peso da porção de água, $\theta$ o ângulo de inclinação do terreno e $\mathrm{F}$ a força que a bomba exerce na porção de água temos: 


$$
\begin{gathered}
T_{P_{X}}+T_{F}=\frac{m \cdot v^{2}}{2}-\frac{m \cdot v_{0}^{2}}{2} \\
-m \cdot g \cdot \operatorname{sen} \theta \cdot \Delta s+T_{F}=\frac{m \cdot v^{2}}{2}-\frac{m \cdot v_{0}^{2}}{2}
\end{gathered}
$$

Fazendo $m=d \cdot V$ e sendo $v_{0}=0$, vem:

$$
-d \cdot V \cdot g \cdot \operatorname{sen} \theta \cdot \Delta s+T_{F}=\frac{d \cdot V \cdot v^{2}}{2}
$$

Dividindo ambos os termos por $\Delta t$ temos;

$$
-\frac{d \cdot V \cdot g \cdot \operatorname{sen} \theta \cdot \Delta s}{\Delta s}+\frac{T_{F}}{\Delta t}=\frac{d \cdot V \cdot v^{2}}{2 \cdot \Delta t}
$$

Fazendo $\mathrm{L}=\frac{\mathrm{v}}{\Delta \mathrm{t}}$ (vazão), $P_{b}=\frac{T_{F}}{\Delta t}$ (potência da bomba) e d $=1000 \mathrm{~kg} / \mathrm{m}^{3}$, vem;

$$
\begin{gathered}
-1000 \cdot L \cdot \operatorname{sen} \theta \cdot \Delta s+P_{b}=\frac{d \cdot L \cdot v^{2}}{2} \\
P_{b}=1000 \cdot L \cdot\left(\frac{v^{2}}{2}+g \cdot \operatorname{sen} \theta \cdot \Delta s\right)
\end{gathered}
$$

onde:

- L, vazão;

- v, velocidade da saída de água;

- g, aceleração da gravidade;

- $\Delta s$, distância de bombeamento. 


\section{CONCLUSÕES}

Após a realização dos cálculos e associações entre vazão de água, potência necessária para o serviço e a quantidade de tempo que a reserva de água sustenta o bombeamento, pode-se afirmar que existe relações analíticas entre o tipo de motor e a potência mais adequada para a irrigação.

Desta forma, a avaliação do desempenho de motores elétrico de baixa potência no bombeamento de água pode ser realizada através de métodos pertinentes à Física e ao Cálculo Diferencial e Integral, sendo assim possível mostrar uma das várias aplicações de tais teorias.

Assim, os métodos matemáticos foram utilizados para a avaliação do desempenho do motor e conceitos da Física para a determinação e associação entre potência dissipada e vazão de água.

Por fim, vale ressaltar que de acordo com os cálculos realizados, pode-se afirmar também que é possível associar motores elétricos ao tipo de serviço (dimensionamento) que é recomendado para o seu uso.

\section{REFERÊNCIAS}

LEITHOLD, L. O cálculo com geometria analítica; v. 1, São Paulo. Editora: Harbra, 1994. $3^{\circ}$ edição.

CALÇADA, C. S.: SAMPAIO, J. L. Física Clássica: Dinâmica Estática; São Paulo. Editora: Atual, 1998. 